after $75 \mathrm{~h}$, it can be concluded that the withdrawal syndrome from the prior drug administration was the principal contributor to the observed fighting.

The delay in onset of vigorous fighting by the morphine groups is relatively uniform and corresponds with the delay noted by Thor \& Teel (1968), who used terminal dosages of 100,200 , and $400 \mathrm{mg} / \mathrm{kg} /$ day. The interval prior to onset, as well as the duration, of vigorous and sustained fighting may thus be independent of prior dosage level above the threshold for fighting. The more apparent explanation is that fighting is due to emotional hyperirritability that parallels peak withdrawal distress. Time of maximum distress according to prior dosage, however, is presently unknown for the rat, but observation of a number of groups at a range of terminal dosages of morphine ( $50-600 \mathrm{mg} / \mathrm{kg} / \mathrm{day}$ ) supports the consideration that peak of withdrawal stress occurs between 3 and 4 days after the terminal dose.

Continuous and automated monitoring of group cages for loud vocalization appears to be a useful method for unambiguous recording of spontaneous drug-induced fighting behavior in rats. REFERENCES

BARNETT, S. A. The rat: $A$ study in behavior. Chicago: Aldine, 1963.

BARNETT, S. A. Rats. Scientific American, $1967,216,78-85$.
BOSHKA, S. C., WEISMAN, H. M., \& THOR, D. H. A technique for inducing aggression in rats utilizing morphine withdrawal. Psychological Record, 1966, 16, 541-543.

EIBL-EIBESFELDT, I. The fighting behavior of animals. Scientific American, 1961, 205, 112-122.

FLOREA, J., \& THOR, D. H. Drug withdrawal and fighting in rats. Psychonomic Science, $1968,12,33-34$.

LORENZ, K. On aggression. New York: Harcourt, Brace \& World, 1966.

MOYER, K. E, A preliminary physiological model of aggressive behavior. Paper presented at the meeting of the American Association for the Advancement of Science, Dallas, December 1968.

SCOTT, J. P. Agonistic behavior of mice and rats: A review. American Zoologist, 1966, 6, 683-701.

SCOTT, J. P. Theoretical issues concerning the origin and causes of fighting. Paper presented at the meeting of the American Association for the Advancement of Science, Dallas, December 1968.

THOR, D. H. Chemical induction of traumatic fighting. Proceedings of the 77 th annual convention of the American Psychological Association, 1969, Part 2, 883.

THOR, D. H., \& TEEL, B. G. Fighting of rats during post-morphine withdrawal: Effect of prewithdrawal dosage. American Journal of Psychology, 1968, 81, 439-442.

ULRICH, R. E., \& AZRIN, N. H. Reflexive fighting in response to aversive stimulation. Journal of the Experimental Analysis of Behavior, 1962, 5, 511-520.

\section{NOTE}

1. This work was supported in part by United States PHS Grant MH 17402-01.

\title{
Extinction of free-operant avoidance behavior using a three-ply schedule
}

\section{DAVID D. BURNSTEIN, State University College of New York at Potsdam, Potsdam, N.Y. 13676}

Four rats were trained on a three-ply avoidance schedule of $R-S 9.5 \quad S-S 2$, $R-S 15 \quad S-S 5$, and $R-S 30 \quad S-S 15$. An extinction leg was then substituted for one of the avoidance legs. Results indicated that by using this procedure, extinction took place within the 1 -h leg. Responding during the extinction was a function of the strength of the avoidance response without respect to any of the avoidance schedules. The data indicated only one case of a discrimination based on repeated extinction-avoidance training.

The usual extinction procedure for avoidance training is the removal of the shock from the experimental situation. Studies using this procedure have found differences in the persistence of the avoidance behavior. Sidman (1955) found no performance decrement in 15-min environment cubicle, was used. Experimental contingencies were controlled by standard programming equipment. Data were recorded on counters and a Gerbrands cumulative recorder. A shock of $2-\mathrm{mA}$ intensity for a $0.2-\mathrm{sec}$ duration was delivered by a Grason-Stadler shock generator. Schedule changes within a session were made manually.

\section{PROCEDURE}

The Ss were run in 3-h sessions every other day except Sunday. The training schedule was a three-ply free operant avoidance schedule consisting of 1-h legs of R-S 9.5 S-S 2, R-S 15 S-S 5, and R-S 30 S-S 15. The legs of the schedule were counterbalanced across sessions. Ss had from 180 to $219 \mathrm{~h}$ on the training schedule.

\section{First Extinction}

One of the avoidance legs of the three-ply schedule was replaced by an extinction leg. The legs were counterbalanced over four sessions, but with the extinction leg in either the second or third position. After four sessions with an extinction probe, the training schedule was run for two sessions. The extinction procedure was repeated until each of the avoidance schedules had been replaced by an extinction probe. A total of 12 extinction sessions were run under this procedure.

\section{Second Extinction}

Following the first extinction, the procedure was changed so that in each session a different avoidance leg was replaced by the extinction leg. The legs were counterbalanced across sessions, with the extinction leg occurring in either the second or third position. A total of 12 extinction sessions were run under this procedure.

\section{RESULTS AND DISCUSSION}

An indication of the baseline avoidance behavior can be seen from the pre-15-min extinction intervals in Fig. 1. The median responses during the $15 \mathrm{~min}$ before the extinction leg differ for each $S$, but the inverse relationship between $R-S$ intervals and median response is the same for each $S$. The median response is highest for the R-S 9.5 and lowest for the R-S 30.

The median response for each 15-min segment of the 1 -h extinction leg is shown in Fig. 1. For $S 4$ and $S 6$, these curves decrease as a function of time into the extinction leg. The trend is the same regardless of the preceding avoidance schedule. For S 2, only the extinction when preceded by an R-S 30 deviates from the decreasing median response pattern and then only for the first $15 \mathrm{~min}$ of 

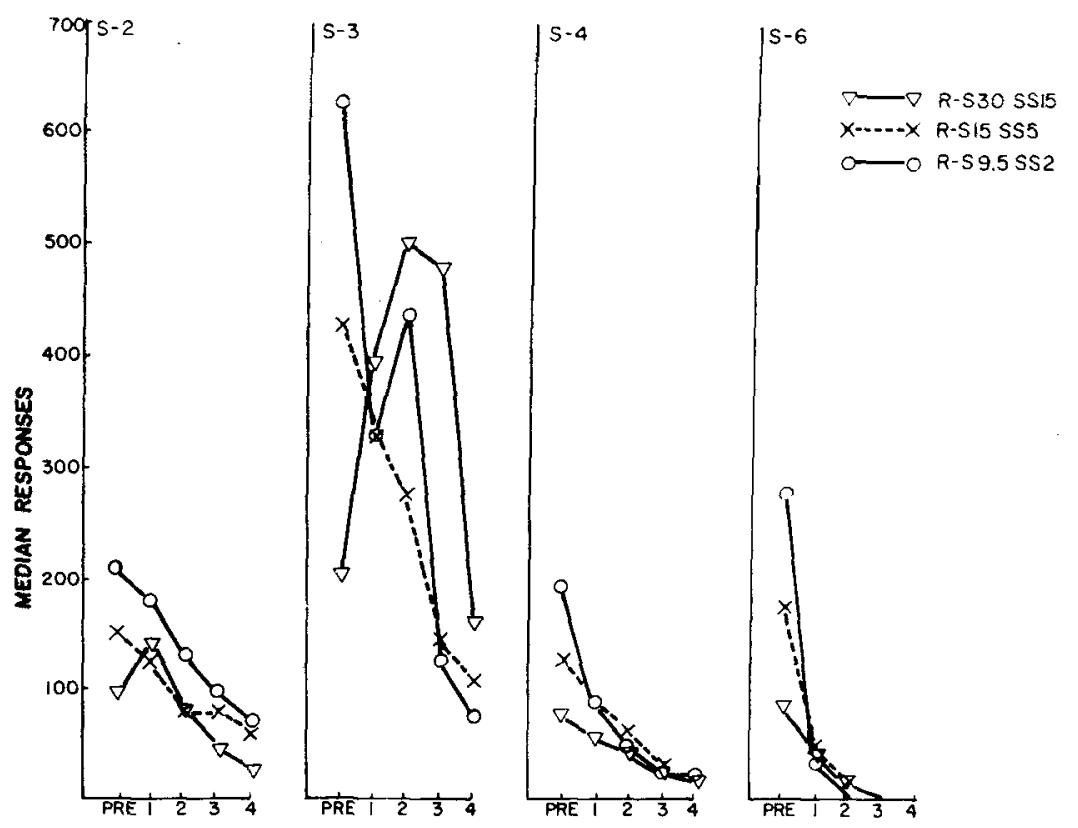

I5 MINUTE EXTINCTION SEGMENTS

extinction. The behavior during extinction for S 3 is unsystematic except when the R-S 15 preceded extinction. The extinction preceded by the R-S 30 interval shows an increase in responding relative to the pre-15-min interval rather than a decrease in responding except for the last $15 \mathrm{~min}$. The extinction preceded by the R-S 9.5 interval shows an increase in responses during the second 15-min interval, while the other points show the decrease in responding.

Analysis of the cumulative records indicated that none of the $\mathrm{Ss}$ received more than one shock during any S-S interval. Since the number of shocks the $S$ could receive was determined by the $R-S$ interval, an efficiency index was computed to determine how well the Ss were avoiding the shock. The number of shocks the Ss avoided was divided by the total number of shocks possible in any particular avoidance leg. This was converted to a percentage.

As seen in Table 1, S 6 had the poorest avoidance behavior, only avoiding $73 \%$ of the shocks during the R-S $30 \mathrm{~S}-\mathrm{S} 15 \mathrm{leg}$. S 3 had the best avoidance behavior, avoiding the shock no less than $97 \%$ of the time.

Table 1

The Mean Efficiency of Avoidance Responding During the $1 \mathrm{H}$ Avoidance Legs of the ThreePly Schedule When Extinction was One of the Schedules

\begin{tabular}{lccc}
\multicolumn{5}{c}{ One of the Schedules } \\
\hline Subject & $\begin{array}{c}\text { R-S 9.5 } \\
\text { S-S 2 }\end{array}$ & $\begin{array}{c}\text { R-S 15 } \\
\text { S-S 2 }\end{array}$ & $\begin{array}{c}\text { R-S 30 } \\
\text { S-S I5 }\end{array}$ \\
\hline S-2 & $90 \%$ & $94 \%$ & $96 \%$ \\
S -3 & $98 \%$ & $98 \%$ & $97 \%$ \\
S-4 & $71 \%$ & $78 \%$ & $81 \%$ \\
S-6 & $63 \%$ & $66 \%$ & $73 \%$ \\
\hline
\end{tabular}

The three-ply avoidance schedule would have to be considered a multiple schedule, with the external stimulus being the shock or R-S interval. The more poorly developed the avoidance response, the greater the probability of the R-S interval occurring. During extinction, inefficient avoidance behavior provides more rapid feedback to the $S$ that the shock is no longer in effect; hence, the rapid extinction curves for $\mathrm{S} 4$ and $S 6 . S 2$ and $S 3$ were efficient avoiders under each of the three schedules. Although the absence of shock for a long IRT during extinction would also constitute feedback for these Ss, the frequency of occurrence of long IRTs Juring the initial $15 \mathrm{~min}$ of extinction was

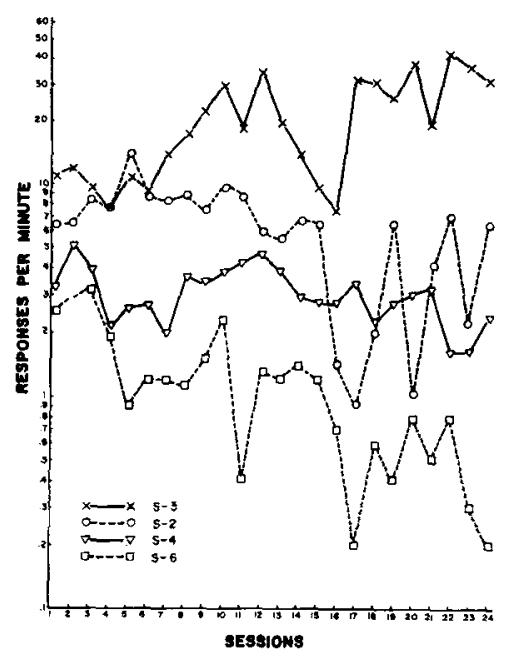

Fig. 2. Response rate per minute for the 2Y 1-h extinction sessions plotted on a three-cycle log vertical coordinate.
Fig. 1. Median responses made during successive 15-min intervals when an R-S 30 S-S 15, an R-S 15 S-S 5, or an R-S 9.5 S-S 2 avoidance schedule preceded the extinction. Each curve represents the median response for eight sessions.

less for S 2 and S 3 than for S 4 and S 6 . The extinction curves for $\mathrm{S} 2$ were more likely due to the cyclic fluctuations that develop in avoidance behavior (Sidman, $1955,1958,1960)$. The behavior of S 3 during extinction is best characterized in terms of his behavior during the avoidance schedules. The behavior consisted of long bursts of responding interspersed with periods of IRTs appropriate to avoidance schedules. This behavior carried over into the extinction legs of the schedule.

Since 24 extinctions were run, the development of discriminative extinction (Boren \& Sidman, 1957; Boren, Sidman, \& Herrnstein, 1958) could be a by-product of the design. Figure 2 indicates that the only decreasing response rate over sessions was for $S 6$.

Most of the responses during extinction occurred in the first $15 \mathrm{~min}$ for all $\mathrm{Ss}$ except $S 3$. The response rate during this period was unrelated to the previous avoidance schedule. Persistence of the avoidance response was a function of the strength of the avoidance responding, i.e., how efficiently the $S$ avoided the aversive stimulus. The use of an avoidance extinction baseline should be limited to periods of less than $1 \mathrm{~h}$ due to its rapid negative acceleration. The data confirm Shnidman (1968). The nature of the extinction curve appears to be predictable based on the strength of the avoidance responding; however, total number of responses during extinction or time to reach some extinction criteria poorly describe the nature of the extinction curves.

\section{REFERENCES}

BOREN, J. J., \& SIDMAN, M. A discrimination based upon repeated conditioning and extinction of avoidance behavior. Journal of Comparative \& Physiological Psychology, $1957,50,18-22$.

BOREN, J. J., SIDMAN, M., \& HER RNSTEIN, R. J. Avoidance escape and extinction as a function of shock intensity. Journal of Comparative \& Physiological Psychology, $1959,52,420-425$.

SIDMAN, M. On the persistence of avoidance behavior. Journal of Abnormal \& Social Psychology, 1955, 50, 217-220.

SIDMAN, M. Tactics of scientific research. New York: Basic Books, 1960.

SIDMAN, M. Some notes on "Bursts" in free-operant avoidance experiments. Journal of the Experimental Analysis of Behavior, 1958, $1,167-172$.

SHNIDMAN, S. R. Extinction of Sidman avoidance behavior, Journal of the Experimental Analysis of Behavior, 1968, 11, 153-157. 